\title{
VIDEO-ASSISTED MINIMALLY INVASIVE MITRAL VALVE SURGERY: THE "MICRO-MITRAL" OPERATION
}

W. Randolph Chitwood, Jr., MD, Joseph R. Elbeery, MD, William H. H. Chapman, MD, Jon M. Moran, MD, Robert L. Lust, PhD, William A. Wooden, MD, and David H. Deaton, MD, Greenville, N.C.

Over the past 15 years, repair techniques, improved prostheses, retrograde cardioplegia, and enhanced exposure collectively have led to impressive advances in mitral valve surgery. Just as minimally invasive coronary surgery appears efficacious, cardiac valve operations using similar techniques are promising. Recently, Kaneko and associates ${ }^{1}$ reported videoscopic examination of the mitral valve during a commissurotomy done via a sternotomy. Early this year, port-access mitral replacements were done in Malaysia by the Stanford team using new aortic balloon occlusive technology. On February 26, 1996, Carpentier successfully performed the first video-assisted mitral valve repair through a minithoracotomy during ventricular fibrillation. ${ }^{2}$ On May 26, 1996, our group performed a direct vision "micro-mitral" valve repair with antegrade cardioplegic arrest through a 2.4-inch incision. Two days later we replaced a rheumatic mitral valve using a video-assisted minimally invasive approach, and this case is the subject of this report.

The patient was a 43-year-old man with diabetes and long-standing mitral insufficiency that had progressed to class III heart failure and recent-onset atrial fibrillation. Cardiac catheterization showed normal coronary arteries and a 0.45 ventricular ejection fraction. Transthoracic echocardiography showed an immobile posterior leaflet with type III severe mitral insufficiency. Intraoperative transesophageal echocardiography confirmed the transthoracic study. The patient was intubated with a double-lumen endotracheal tube for single lung ventilation and positioned with the right side of the chest elevated 45 degrees and the pelvis nearly flat. A 2-inch incision was made in the midaxillary line over the fifth rib and a small section was removed. A custom retractor was used to provide operative exposure (SnowdenPencer Inc.). The pericardium was opened just anterior to the phrenic nerve with thoracoscopy scissors. Specialized instruments were used throughout the operation: however, video access was established by means of standard thoracoscopic techniques. A $10 \mathrm{~mm}$ thoracoscopic port was placed posterior and cephalad to the main incision, and a three-chip lighted camera (Linvatec Inc.) was inserted to visualize the limited surgical field.

Peripheral cardiopulmonary support $\left(28^{\circ} \mathrm{C}\right)$ was estab-

From the Minimally Invasive Surgery Workgroup, Department of Surgery, East Carolina University School of Medicine, Greenville, N.C.

Received for publication June 18, 1996; accepted for publication July 25, 1996.

J Thorac Cardiovasc Surg 1997;113:413-4

Copyright (c) 1997 by Mosby-Year Book, Inc.

$0022-5223 / 97 \$ 5.00+0 \quad \mathbf{1 2 / 5 4 / 7 6 9 2 0}$ lished via the right femoral vessels with a $29 \mathrm{~F}$ BioMedicus venous return cannula (Medtronic Bio-Medicus) positioned in the mid-right atrium for suction drainage to provide cardiac decompression. A catheter was placed retrogradely in the right atrial coronary sinus with the aid of transesophageal echocardiography. A specially designed transthoracic aortic crossclamp (Scanlan International) was introduced through a tiny posterior axillary line incision and passed anterior to the superior vena cava to occlude the ascending aorta just below the innominate artery. To access the valve, the interatrial groove was dissected with thoracoscopic scissors and a left atriotomy performed with exposure provided by a ribbon retractor. Excision of the anterior leaflet, valve suture placement, prosthesis seating, and knot tying were done exclusively with the use of camera/monitor visualization (Fig. 1, $A$ ). Valve sizing was done with minor modifications to standard sizers. In most instances, valve suture placement by means of "secondary vision" was not difficult through the incision. Suture placement was amazingly easy in the left fibrous trigone region but became more difficult near the right fibrous trigone. There was a tendency to place too many sutures because of system magnification. Sutures exiting the access site were kept in order with suture guides. Seating of the $31 \mathrm{~mm}$ St. Jude Medical valve (St. Jude Medical, Inc.) was uncomplicated but knot tying was more difficult (Fig. 1, B). A modified instrument was adequate but tying was not expedient. A transvalvular vent was placed to remove air, and the atrium was closed under direct vision. The operative time was long, with an arrest time of 2 hours 45 minutes, but the patient was extubated the next morning. Three days later, deep venous thrombosis of the right leg developed, which delayed his discharge, but he was treated for this complication without event. The patient never complained of thoracic incisional pain.

This case appears to be the first mitral valve replacement done in the United States with the use of a micro-access incision, video or "secondary" vision, peripheral cardiopulmonary bypass, and retrograde cardioplegia. The cornerstones were the use of standard thoracoscopic video techniques and the development of a new transthoracic aortic crossclamp. The jaws of the transthoracic crossclamp work completely in the chest without impediment by a port or incision entrance site. Others have developed intraluminal balloon methods to occlude the aorta for cardioplegic arrest. ${ }^{3}$ Our procedure offers additional flexibility, inasmuch as small femoral arteries and aortoiliac disease could preclude passage of balloon devices. Moreover, with intraluminal occlusion, radiographic positioning is necessary to assure balloon location within the innominate artery. The elegance of the occlusive technique used in our micro-mitral operation resides in the cost-effectiveness, simplicity, and applica- 

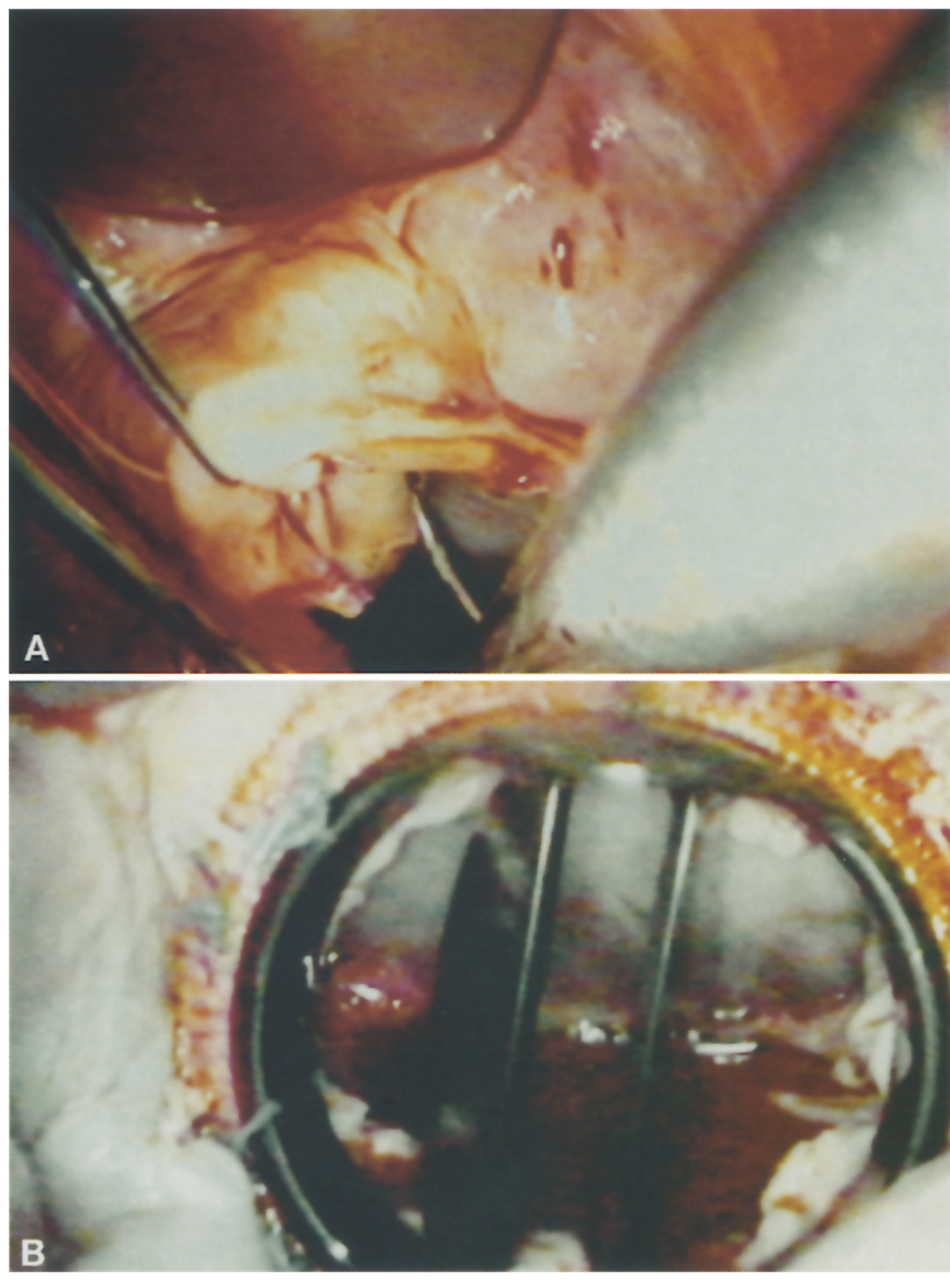

Fig. 1. A, Through the $10 \mathrm{~mm}$ thoracoscopic camera (Linvatec Inc.), the mitral valve is visualized during placement of subannular valve sutures. B, The prosthetic valve is shown through the camera after being seated and after suture knots were tied through the 2 -inch incision with a modified instrument.

bility to nearly all patients with pliable aortas. Femoral cannulation still appears to be an Achilles' heel of all micro-access operations, and new methods for efficient transthoracic cannulation need to be developed.

\section{REFERENCES}

1. Kaneko Y, Kohno T, Ohtsuka T, Ohbuchi T, Furuse A,Konishi $T$. Video-assisted observation in mitral valve surgery. J Thorac Cardiovasc Surg 1996;111:279-80.
2. Carpentier A, Loulmte D, Carpentier A. Chirugie à coeur ouvert par vidéo-chirurgie et mini-thoracotomie-primier cas (valvuloplastie mitrale) opéré avec succès [First open heart operation (mitral valvuloplasty) under videosurgery through a minithoracotomy]. Comptes Rendus De L'Academie des Sciences: Sciences de la vie 1996;319:219. 23.

3. Schwartz DS, Ribakove GH, Grossi EA. Minimally invasive cardiopulmonary bypass with cardioplegic arrest: a closed chest technique with equivalent myocardial protection. J Thorac Cardiovasc Surg 1996;111:556-66. 